\title{
Constructing a Social Work Environmental Dialogue
}

\author{
Venkat Pulla ${ }^{1, *}$, Suresh Pathare ${ }^{2}$ \\ ${ }^{1}$ Institute of Land, Water and Society (ILWS), Charles Sturt University, Wagga Wagga, Australia \\ ${ }^{2}$ CSRD Institute of Social Work and Research, Ahmednagar, Maharashtra, India
}

\begin{abstract}
Modern behaviours supported by ignorance and greed have impacted on the environment and have left many scars that will take lifetimes to rectify. This paper proposes that the social work profession has apparently played no leadership role in alerting society to the dangers of environmental change; albeit individual social worker's campaigns against exploitation of the environment are exceptions. Within the South Asian scenario, social workers such as Medha Patkar continue to crusade for environmental justice making it clear that collective advocacy is needed. The authors assert that the social work literature shows limited interest, consideration and therefore, no debate around climate change. The authors explore a role for social work and argue merits for a social work role in the environmental dialogue. A construction of social work taking a central role has been proposed, that requires a new perspective focused on society and its problems and the values of the profession.
\end{abstract}

Keywords Ecological Social Work, Environmentalism, Climate Change, Human Rights Approach

\section{Introduction}

The social work profession seems to be at odds with recognising societal dangers of environmental change, with professional literature precluding any sustained interest, consideration and debate around environmental change (Coates 2003; Zapf 2009; Pulla, 2014). Coates (2003) proposed that this is due to social work's birth and alignment to modern paradigms despite dominant modern priorities of consumerism being at odds with the core elements of social work and values. Human ignorance surrounding the impact of modern behaviours on the environment impels harmful and dramatic consequences. In order to minimise those harmful impacts, long-term humanistic goals and common and shared values are required. By default, impacts of environmental change produce conditions that affect every aspect of our lives and the environment in which we live and on which we depend; making environmental change a risk management issue with increasingly dangerous outcomes as we take longer to act. Clearly, modern society appears unwilling or unable to comprehend the threat associated with environmental change. Neuroscientists and behavioural psychologists have likened this to the fact that our response systems are triggered when our survival is at stake; however, global warming does not trigger those types of automatic responses as this unprecedented threat is moving slowly compared to the threats that our ancestors faced (Gore, 2009). This lack of comprehension may explain the reluctance of the existing paradigm within social work that do not adequately address social work's role in environmental change.

As social work professionals, we see our role in promoting social change, problem-solving in human relationships and the empowerment and liberation of people to enhance well-being. We do this with the understanding gained from human behaviour and social systems and intervene at the points where people interact with their environments. However, our social work practice predominantly understands the concept of 'environment' as a social or cultural environment, as opposed to the natural environment (Coates 2003; McKinnon 2008; Zapf 2009, Pulla, 2014). An ecological model forwarded by Gitterman and Germain (2008) explains that the "person and environment are engaged in constant circular exchanges in which each is reciprocally shaping and influencing the other over time' $(p, 34)$. The acknowledgement of the physical and social gives credence to the fact that environmental justice issues bare weight on social justice issues as they emphasise that humans are intrinsically embedded into the wider environment (Hoff \& Polack, 1993; Marlow \& Van Rooyen 2001). The authors have identified a practice gap in which social workers appear to see social justice not being inclusive of nurture, care and preservation of the natural environment. This is despite the expressed commitment of social work to principles of human rights and social justice being fundamental to social work practice.

Social work needs to disentangle from its modernist beginnings to close the theory to practice gap, and include environmental concerns in its all curriculum. The authors feel that there needs to be a substantial debate on the environmental interface in social work and an extension of 
social work theories. These theories should aim to incorporate alternative discourses which support a new way of thinking in social work and facilitate social system's mutually interdependent relationship with the natural environment and the resultant linkage of social justice with environmental justice. Marlow and Van Rooyen (2001, p. 253) stated that:

"The environmental crisis is growing in momentum and if social workers are to be responsible to clients and communities they need to make a planned and concerted effort to systematically address both theoretical and practical responses".

\section{The Primacy of Social Work}

The impacts of climate change are felt in all societies as threats to access food, a roof over their head and right to life. Fundamental human rights such as the above are inclusive of the rights to life, to food, and to a place to live have been largely ignored even in the western world, despite all party's consent and agreement to the United Nations Kyoto Protocol (1998, Article 10d) which states:

Cooperate in scientific and technical research and promote the maintenance and the development of systematic observation systems and development of data archives to reduce uncertainties related to the climate system, the adverse impacts of climate change and the economic and social consequences of various responses...

The Intergovernmental Panel on Climate Change, IPCC (2007) has identified that promoting interactions between the public and private decision-making processes will support cooperative efforts to reduce climate change when underpinned by an equitable and decentralised decision-making process. Coates (2003) advised of the need for a paradigmatic shift that enables social workers to take a lead in transforming global consciousness and environmental wellbeing. The United Nations Kyoto Protocol (1998, Article 2) requires principles of collaboration, cooperation, information exchange, and transparency to be facilitated across Government and Intergovernmental mechanisms towards the inclusion of social workers. This process will enable scientific knowledge to be merged with human wisdom from a variety of sources, to build an ecologically sustainable model which furthers the public awareness and political change required to lay the groundwork for sustainable development paths (Hoff \& Polack, 1993; WCED, 1987). With this in mind, the scene has been well and truly set for the social work profession to partake in the climate change debate and help advance more sensible humane adaptations

The United Nations have acknowledged that achieving sustainable development in climate change adaptations will require widespread support and involvement from across the community (UN, 1987, chapter 1: section 96). They have identified that the roles of Non-government organisations (NGOs) in this is an important one, stating their participation in planning, decision-making and implementation should be expanded (UN, 1987, chapter 1: section 96). NGOs are one of the main stakeholders in climate change solution development, recognised in particular for their sphere of influence (Giddens, 2011). NGOs are perceived as having and providing strong leadership, a capacity to build trust, the capacity to raise community awareness, and an ability to build collaborative practices with a wide variety of organisations (UN, 1987). NGOs have been involved in setting environmental change policy in many countries, through their prompting of wide-spread government actions given their historical influence in creating public awareness and political pressures through the coordination and dissemination of relevant information and bringing it to the notice of decision makers and the public (Giddens, 2011; UN, 1987, chapter 12: section 66). NGOs can be used as a platform to translate scientific evidence into accessible information for use by decision makers and the public (UN, 1987, chapter 12: section 69). The magnitude and consequences of this have been summarised by the World Commission on Environment and Development (1987, p. 8).

\section{Pragmatism and Social Work}

The IFSW-IASSW Definition of Social Work (Appendix 1) states that social work intervenes at the points where people interact with their environments (Ifsworg, 2016). The International Federation of Social Workers explains the social workers' ethical role in terms of their obligation to challenge unjust policies and practices and to seek solutions based on solidarity.

"Yet in recent years, social work has been mainly pre-occupied with people's social environment and not so much with the natural environment. This was not the case in the 19th and early 20th century when the early social workers campaigned with others around the world for improvements in public health and the built environment [housing and public spaces]. Our communities have been rediscovering that a positive social environment is not possible without a sustainable natural environment. It is generally accepted that our natural environment not only influences but also is crucial for our social lives now and in the future" (IFSWORG, 2016).

Vulnerability reduction is a core component of adaptation and disaster risk management (IPCC, 2012). With individuals and groups within all societies having insufficient capacity to adapt to climate change, research has shown that building human and social capital are key 
determinants of adaptive capacity at all levels (Adger, Agrawala, Mirza, Conde, O'Brien, Pulhin, Pulwarty, Smit, and Takahashi (2007). Hoff and Polack (1993) summarise the concerns of numerous social work commentators, including Brogan and James (1980); Moroney (1981); and the WCED (1987), regarding the fact that 'degradation of the physical environment contributes to many urban ills such as crime, suicide, apathy, and mental illness'. Social works understanding of social capital and its demonstrated awareness of social implications makes it best suited to help advance environmental change adaptations. Outside of the recognised need to review social work practice theories, social work commentators have begun to hypothesis the best ways for social workers to offer a pragmatic social work response. Narhi (2004) has pointed ways by which social workers can reflect and support environmental practices

\section{Considering the Research Potential of Social Work}

As illustrated above, social work approaches are useful in evaluation and research; environmental education; community development; advocacy; and influencing of social and environmental policy. Before any serious steps can be undertaken by the profession towards building a presence in the climate change debate, social workers must first turn their attention to building an understanding of what this means for their professional practice. The authors believe that at its essence, this needs to be implemented at a pedagogical level in our schools of social work with a review of social work education to incorporate elements of eco-social work and sustainability into our training. This will be discussed at a later stage in this paper.

An important step in this direction is to increase a practitioner's knowledge through involvement in the evaluation of personal knowledge, an undertaking of empirical research, and the development of theoretical knowledge, procedural knowledge and practical knowledge. If social workers are to come to the table with their expertise respected, they have a responsibility to be able to undertake research which can be shared with economists, environmentalists, scientists, politicians and the community, to build an understanding of socio-economic trends and impacts regarding environmental change vulnerability. With limited information being available on many social and economic impacts, social workers have a responsibility to contribute to the development of the body of research which will inform adaptation measures and climate change risks (Hennessy et al., 2007). The research will assist inform Risk, Impact \& Evaluation Assessments that will assist with the identification of climate change vulnerabilities.

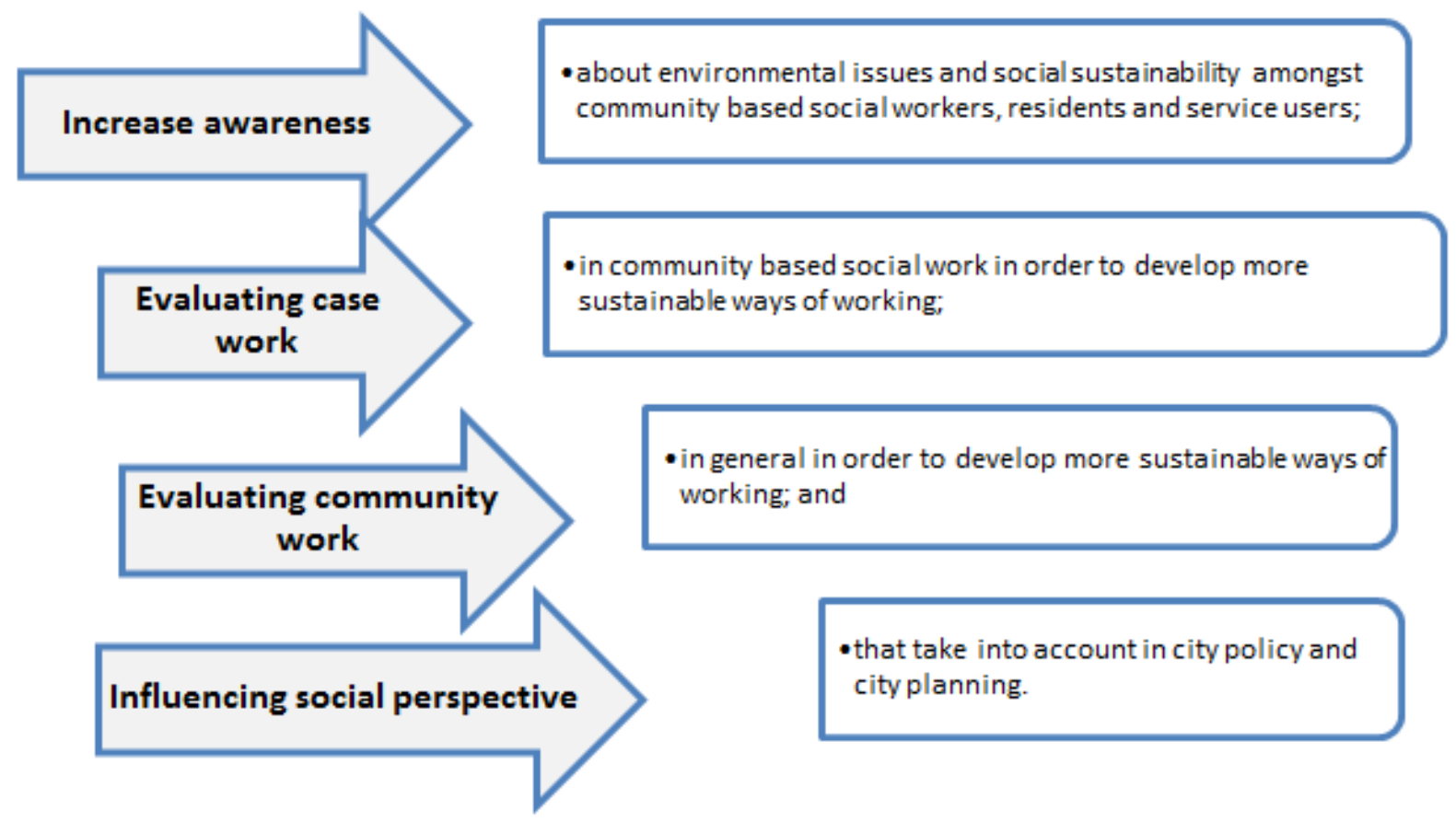

Figure 1. Adaption of Ideas from Nahri 2004 
Furthermore, social workers need to investigate research on the resilience of socio-ecological systems to climate change (Adger et al., 2007), as many adaptation initiatives will need to incorporate systems which aim to reduce societal vulnerability and monitor and evaluate the ancillary effects of such measures. It has been proposed that the distinction between the studies of how much change in socio-economic conditions affects vulnerability to climate change rather than how welfare is affected by changing socio-economic conditions, will help build a better understanding of key vulnerabilities to climate change and how adaptation will be received through various human and natural systems (Schneider et al., 2007). While socio-economic research has additional benefits of supporting the development of eco-social policies and stakeholder planning, the social work profession needs to have this information for our own analysis and planning. This will assist with managing the impact that climate change and any adaptation measures will have on social costs, human rights, sustainability, and community development and resettlement (Adger et al., 2007). The social work profession should also expand research into the discriminatory effects of climate change to inform the community on our capacity to undertake community development and education (Hoff \& Polack, 1993).

\section{Educational Strategies}

Once empowered with research and knowledge, social workers can use education to build an increased awareness of environmental issues across a number of areas (Marlow \& Van Rooyen, 2001). The Kyoto Protocol (United Nations, 1998, Article 10) states that parties will 'us(e) existing bodies, (in) the development and implementation of education and training programmes, including the strengthening of national capacity building... and facilitate at the national level public awareness of, and public access to information on, climate change'. As an actor in this field, social workers can use this as part of a comprehensive communication strategy, to raise awareness of climate change impacts with clients, stakeholders and the government. Having identified that face-to-face communication is vital in knowledge sharing, and with the understanding that social workers have a capacity to build trust, we, in turn, have the foundation to raise community awareness.

Current potential areas for adaptation identified under Capacity Building and Natural Disaster Management conclude that education will build personal awareness and social knowledge surrounding climate change increasing community capacity to work with emergency services on disaster management. These elements can be integrated into the delivery of educational programs and social work initiatives, such community development programs aim to reduce vulnerability to climate change (Yohe et al., 2007).

\section{Aspects of Community Work}

Social workers have a historical involvement in community development, setting the foundation for a community focus which aims to engage the principles and skill sets surrounding community work. Undertaking a human rights-based approach to environmental community development, social workers can focus on strengthening communities from the bottom up, empowering communities to build on their own coping strategies and to advocate for environmental responsibility through the development of climate change policies. Adaptation policies should focus on strengthening resilience (Giddens, 2011) with community organisations noted as an effective strategy to build resilience (Adger, et al., 2007). Through involvement in successful community-based resource management, social workers can potentially enhance the resilience of communities and have the ability to preserve ecosystem resilience. Resilience themes run through potential areas of adaptation in capacity building, settlements, and infrastructural planning. In the latter, working with rural communities to build resilience assumes particular importance, with mental health impacts on farming and rural communities.

Notions of sustainability will continue to be crucial to this. Social workers need to move away from the remedial action and into sustainable development to support fundamental human rights and social justice whilst also supporting ecological justice. Sustainability will require the world's consumption to be bound by what is ecologically possible to meet the needs of the present without compromising the ability of future generations to meet their own needs (UN, 1987). Within this, social workers have the potential of acting as a source of expertise in matters pertaining to eco-socially sustainable and inclusive living environments given our micro-level practical knowledge of community sustainability (Narhi, 2004).

One of the most significant contributions social workers can make towards climate change adaptation is building an ability to promote social sustainability that encompasses ecological and economic dimensions (McKinnon, 2008; WCED, 1987). Social workers have a duty to bring to the climate change debate their knowledge about the relationship between the living environment and human welfare to progress eco-social sustainability. The United Nations have called for sustainable development to meet the basic needs of all, reducing poverty and inequity and in turn vulnerability to ecological and other crises (UN, 1987). The crisis of the relationship between humans and nature needs to be addressed at a societal level since it is this inequity, or power differential, which is fundamental to the majority of environmental and development challenges. To overcome this, community development needs to encompass coalition building and policy advocacy across stakeholder and government networks (Hoff \& Polack, 
1993). It is here that the field of social work can pioneer climate change adaptations as mechanisms which support equity.

\section{Simultaneous Advocacy}

Social workers meet their responsibilities by engaging in actions that promote societal and environmental wellbeing, advocate for equitable distribution of resources and effect positive social change in the interests of social justice. They are mandated to advocate for the protection of the natural environment given its fundamental link to humanity. Through advocacy, social workers can bring forward community viewpoints, approaches and goals that combine to provide insight into climate change and adaptation knowledge base (IPCC, 2012). Advocacy will enable the social work profession to highlight potential areas of adaptation mechanisms such as mainstreaming climate change adaptation and the establishment of required social systems. Social Justice includes seeking intergenerational justice (Hoff \& Polack, 1993) and if incorporated with a human rights-based approach, will include excluded and marginalised populations; encourage accountability and transparency in policy decisions; encourage participatory and democratic processes; and build the capacity of key stakeholders through the strengthening of social cohesion. Building the capacity of stakeholders will give people an active role in connecting to, and participating in, climate change adaptations (Gore, 2009). By creating this role, social workers can move into policy development by harnessing the public's resultant emotional correlation to shape public opinion by building the shared values that sustain the long-term collective commitment required. Through the advocating of public policies, social workers can play a vital role in establishing what future is passed onto the next generation by acknowledging multiple stressors and through addressing different priorities and competing goals (IPCC, 2012; Whitaker, 2007).

\section{Social Policy}

An eco-social social work practice theory supports the interface of ecological and social issues and enables social workers to engage in policy influence (Narhi, 2004). By integrating human rights, social justice and environmental needs, social workers can undertake political action in line with sustainability and social work values. This, of course, will require the combination of all of the above areas of research, education, community development models and advocacy skills to drive a high degree of public and political interest required to motivate political responses since the limited ability to cost many social impacts of climate change means these effects are often poorly reflected in estimates of losses and resultant future planning (IPCC, 2012; UN, 1987).

\section{The Pedagogical Approach to Social Work Education}

For social workers to undertake the practice changes which are fundamental to the environmental crisis, revolutionary changes are required at a pedagogical level (Besthom as cited in Jones, 2010, p. 72). Although out of the scope of this paper, the significance of implementing environmental education for social workers has been discussed by social commentators (Jones, 2010) thus it requires recognition to build upon and strengthen the discussions and movements already happening in this area. It is recognised that education is the most important mechanism for advancing ecological thinking in social workers through the provision of skill and culture development. To support this change social work practice will require a paradigm shift surrounding our professional identity to integrate a conceptualisation of the relationship between humans and the environment. It has been proposed that transformative measures which see social and eco-sustainability incorporated in the social work curriculum and ongoing professional development will support the field's expertise and capabilities by providing social work graduands with the preparation required to consider their practice from an eco-social stance.

Building a professional identity which integrates environmental concerns will expand the ecological consciousness of social workers and provide a clear sense of the interdependence of social and environmental issues. Building change via a transformative learning theory will provide the framework required to encompass both the theory and practice of social work. Critical reflection of assumptions, values, and beliefs of modernity and dominant paradigms will be fundamental to reforming social work discourse and action (Jones, 2010, pp. 73-74). This will require the development of practice models, strategies, and theories, and the leadership of associations such as the National Association of Social Workers in India, NAPSWI, and its counterparts in other countries in South Asia in implementing the practice and training standards of social workers within the South Asian region.

\section{Conclusions}

Climate change has been called one of the greatest social, economic and environmental challenges of our time with extensive implications of global warming sweeping across the world causing sea-level rises, coastal flooding, droughts, increased extreme weather events, heat waves, food and water shortages, increased mortality rates, and increased vector-borne, food-borne and water-borne diseases. Climate change will place a disproportionate burden on the disadvantaged and vulnerable people in all 
societies and south Asian third world countries in particular and must be recognised as the social justice issue it is. Adaptation plans must, therefore, address equity issues and will require a strong social safety net to be established to assist those who may otherwise have difficulty in adapting, i.e. vulnerable groups, such as the aged, the poor and Indigenous communities. Sustainable approaches which address social justice considerations of structural disadvantage and empowerment alongside major ecological considerations will be the most effective way forward. To successfully contribute to addressing structural disadvantage and construct a key role in advancing climate change adaptation mechanisms; the profession of social work needs transformational reform to adopt a broader, ecologically orientated social work practice. Since limited environmental debate and understanding currently occurs within the realm of modern social work practice, a post-modern approach which facilitates a paradigmatic shift that enables social workers to take a lead in transforming global consciousness and environmental well-being will be required.

As new research generates creative strategies and interventions through political, social and economic contexts it has the possibility to provide the transitive effects that the environmental movement, currently one of the most worthwhile social movements, requires (Hoff \& Polack, 1993). To perform any research in environmental contexts akin to social work values, it would be recommended that participatory research processes are modelled, supporting those most marginalised groups in the community to bring forward their own social and cultural context to the research creating a communication channel that enables the transaction of shared experiences in learning, problem definition and design of potential solutions (Yohe et al., 2007). This type of dialogue between researchers, practitioners, communities and governments generates useable knowledge to influence social learning, decision-making and public policy. Quite clearly, the social work profession has a role and responsibility in the climate change debate and in advancing climate change adaptations. The environmental/poverty nexus and the conceptualisation of the relationship between humans and the environment are so evident, that to continue along the current path leaves the social work profession at risk of being negligent through their disregard of the values, ethics and responsibility to pursuing social justice. Working from an eco-social approach will facilitate linkage between environmental and social justice and will build the connection, insight and capacity to practice within the realms of environmental sociology and eco-systems approach (Narhi, 2004). This will necessitate the extension of social work theories to incorporate alternative discourses which support a new way of thinking in social work and facilitates the resultant linkage of social justice with environmental justice.
In this paper, the authors have attempted to construct a role for social work in the climate change debate. Through the analysis of published research, it is evident that progressing social work engagement in the areas of research, education, community development, advocacy and policy, will provide the social work professional with concrete, pragmatic actions. An understanding of this rational transformative approach must start in the social work classrooms, with pedagogical changes that will guide the professional practice of social work for the future.

\section{REFERENCES}

Adger, W., Agrawala, S., Mirza, M., Conde, C., O’Brien, K., Pulhin, J., Pulwarty, R., Smit, B. \& Takahashi, K. (2007) Assessment of adaptation practices, options, constraints and capacity. Climate Change 2007: Impacts, Adaptation and Vulnerability. In M.L. Parry, O.F. Canziani, J.P. Palutikof, P.J. van der Linden and C.E. Hanson (Eds.), Contribution of Working Group II to the Fourth Assessment Report of the Intergovernmental Panel on Climate Change, 717-743, Cambridge, UK: Cambridge University Press

Brogan, D., \& James, R. (1980). Physical environment correlates of psychosocial health among urban residents. American Journal of Community Psychology, 8(5), 507-522 DOI: 10.1007/BF00912589

Coates, J. (2003) Ecology and social work: Toward a new paradigm. Halifax, NS: Fernwood books.

Giddens, A. (2011). The politics of climate change, 2nd ed., Cambridge, UK: Polity Press,

Gitterman, A. \& Germain, C., B. (2008). The life model of social work practice: Advances in theory and practice, 3rd ed., New York: Columbia University Press

Gore, A. (2009). Our choice: A plan to solve the climate crisis, New York: Rodale Inc

Hennessy, K., Fitzharris, B., Bates, B., Harvey, N., Howden, S., Hughes, L., Salinger, J., \& Warrick, R. (2007). Australia and New Zealand. Climate Change 2007: Impacts, Adaptation and Vulnerability. In M.L. Parry, O.F. Canziani, J.P. Palutikof, P.J. van der Linden and C.E. Hanson, (Eds.) A contribution of Working Group II to the Fourth Assessment Report of the Intergovernmental Panel on Climate Change, 507-540, Cambridge, UK: Cambridge University Press

Hoff, M.D. \& Polack, R. J., (1993). Social dimensions of the environmental crisis: Challenges for social work', Social Work 38(2): 204-11.

International Federation of social workers [Ifsworg]. (2016). Globalisation and the environment. Ifsworg policies. Retrieved 2 January 2016, from http://ifsw.org/policies/globalisa tion-and-the-environment/

IPCC (2007). Summary for Policymakers. In B. Metz, O.R. Davidson, P.R. Bosch, R. Dave, L.A. Meyer (eds). Climate Change 2007: Mitigation. A contribution of Working Group III to the Fourth Assessment Report of the Intergovernmental Panel on 
Climate Change, Cambridge, United Kingdom and New York, NY, USA: Cambridge University Press,

IPCC (2012).Summary for Policymakers. In Field, C.B., V. Barros, T.F. Stocker, D. Qin, D.J. Dokken, K.L. Ebi, M.D. Mastrandrea, K.J. Mach, G.-K. Plattner, S.K. Allen, M. Tignor, \& P.M. Midgley (eds.). Managing the Risks of Extreme Events and Disasters to Advance Climate Change Adaptation. A Special Report of Working Groups I and II of the Intergovernmental Panel on Climate Change. 3-21., Cambridge, UK, and New York, USA: Cambridge University Press

Jones, P. (2010). Responding to the ecological crisis: Transformative pathways for social work education, Journal of Social Work Education, 46(1), 67-84

Klein, R., Huq, S., Denton, F., Downing, T., Richels, R., Robinson, J., \& Toth F. (2007). Inter-relationships between adaptation and mitigation. In M.L. Parry, O.F. Canziani, J.P. Palutikof, P.J. van der Linden and C.E. Hanson (Eds.) Climate Change 2007: Impacts, Adaptation and Vulnerability. A contribution of Working Group II to the Fourth Assessment Report of the Intergovernmental Panel on Climate Change, 745-777, Cambridge University Press, Cambridge, UK.

Marlow, C., \& Van Rooyen, C. (2001). How green is the environment in social work? International Social Work, 44(2) 241-254

McKinnon, J., (2008). Exploring the nexus between social work and the environment, Australian Social Work, 61(3), 256-268, doi:org/10.1080/03124070802178275

Moroney, R (1981). Policy analysis within a value theoretical framework. In Gallagher, J. \& Haskins, R. (Eds.). Models for analysis of social policy: An introduction, 78-102, Norwood, New Jersey: Ablex Publishing

Narhi, K. (2004). The eco-social approach in social work and the challenges to the expertise of social work. University of Jyvaskyla, Jyvaskyla

Pulla, V. (2014) Towards the greening of social work practice. International Journal of Innovation, Creativity and change 1(3), 141-165
Schneider, S., Semenov, S., Patwardhan, A., Burton, I., Magadza, C., Oppenheimer, M., Pittock, A., Rahman, A., Smith, J., Suarez, A. \& Yamin, F. (2007). Assessing key vulnerabilities and the risk from climate change. In M.L. Parry, O.F. Canziani, J.P. Palutikof, P.J. van der Linden and C.E. Hanson (Eds.) Climate Change 2007: Impacts, Adaptation and Vulnerability. A contribution of Working Group II to the Fourth Assessment Report of the Intergovernmental Panel on Climate Change, 779-810, Cambridge, UK: Cambridge University Press

United Nations (1998). Kyoto Protocol to the United Nations Framework Convention on Climate Change. Retrieved 9 April 2012 from http://unfccc.int/resource/docs/conv $\mathrm{kp} / \mathrm{kpeng}$.pdf

United Nations (1987). Report of the World Commission on environment and development: Our common future, retrieved 12 August 2012 from http://conspect.nl/pdf/Our_Com mon_Future-Brundtland_Report_1987.pdf

Whitaker, B. (2007). A social worker grandfather thinks about global warming. The new social worker, Spring 2007, 14(2) 4-5, retrieved 6 April 2012 from

http://www.socialworker.com/digitalmag/spring2007.pdf

World Commission on Environment and Development [WCED] (1987). Report of the World Commission on Environment and Development: Our Common Future.

Retrieved 8 July 2012 from http://www.un-documents.net/our-co mmon-future.pdf

Yohe, G., Lasco, R., Ahmad, Q., Arnell, N., Cohen, S., Hope, C., Janetos A. \& Perez, R. (2007). Perspectives on climate change and sustainability. In M.L. Parry, O.F. Canziani, J.P. Palutikof, P.J. van der Linden and C.E. Hanson (Eds.) Climate Change 2007: Impacts, Adaptation and Vulnerability. A contribution of Working Group II to the Fourth Assessment Report of the Intergovernmental Panel on Climate Change, 811-841, Cambridge, UK: Cambridge University Press,

Zapf, M. K. (2009). Social work and the environment: Understanding people and place. Toronto, Canada: Canadian Scholars' Press. 